\title{
Transplante celular: análise funcional, imunocitoquímica e histopatológica em modelo experimental de miocardiopatia isquêmica utilizando diferentes células
}

\author{
Cellular transplant: functional, immunocytochemical and histopathologic analysis in an experimental \\ model of ischemic heat disease using different cells
}

Paulo R. BROFMAN, Katherine A. CARVALHO, Luiz C. GUARITA-SOUZA, Carmen REBELATTO, Paula HANSEN, Alexandra C. SENEGAGLIA, Nelson MYAGUE, Marcos FURUTA, Júlio C. FRANCISCO, Márcia OLANDOSKI

RBCCV 44205-692

\section{Resumo}

Objetivo: Apresentar os resultados funcionais, imunocitoquímicos e histopatológicos, in vitro ou em espécimes cardíacas após isolamento, cultura e co-cultura de células tronco mesenquimais, células mioblásticas esqueléticas e transplantadas e co-transplantadas em animais de laboratório com miocardiopatia isquêmica e fração de ejeção do ventrículo esquerdo menor de $40 \%$.

Método: Foram empregados 72 ratos Wistar, divididos em quatro grupos de acordo com o meio de cultura ou das células injetáveis: Grupo controle em que foi injetado apenas o meio de cultura (22 ratos); Grupo de células tronco mesenquimais (17 ratos); Grupo de células mioblásticas esqueléticas (16 ratos) e grupo co-cultura (17 ratos). Nos estudos imunocitoquímicos, as células foram marcadas com antivimentina, anti-desmina e anti-miosina. Nos estudos histopatológicos, as lâminas foram coradas com Tricômio de Gomori e identificados neovasos e tecido muscular. Na análise funcional, foi medida a fração de ejeção do ventrículo esquerdo em dois momentos do seguimento, uma semana após o infarto do miocárdio e um mês após a injeção.

Resultados: A fração de ejeção do ventrículo esquerdo entre os quatro grupos não apresentou diferença estatística significante $(P=0,276)$, o ecocardiograma de seguimento demonstrou diferença estatística significante $(\mathrm{P}=\mathbf{0 , 0 0 1})$. Essa diferença ocorreu entre o grupo controle e o grupo de células mioblásticas esqueléticas $(\mathrm{P}=\mathbf{0 , 0 3 7})$, entre o grupo controle e o grupo co-cultura $(P<0,001)$ e o grupo de células tronco mesenquimais e o grupo co-cultura $(P=0,025)$. Quando se compararam as medidas obtidas dos dois ecocardiogramas em cada grupo, encontrou-se diferença no grupo controle $(\mathrm{P}=0,005)$ para pior e no grupo co-cultura $(\mathrm{P}=0,006)$ para melhor. No estudo imunocitoquímico in vitro, identificou-se células tronco mesenquimais quando marcou-se com antivimentina e células musculares, com anti-desmina. Nas espécimes cardíacas, identificou-se tecido muscular marcada com anti-desmina e células mioblásticas esqueléticas marcadas com anti-miosina rápida. No estudo histopatológico,

Laboratório de Engenharia e Transplante Celular da Pontifícia Universidade Católica do Paraná

Pesquisa Financiada pelo Fundo Paraná/SETI e Finep/MCT

Endereço de correspondência:

Paulo R Brofman

Rua Gumercindo Mares 150 Vista Alegre

Curitiba- Brasil 80810220

Fone (041) 2711657

E-mail: paulo.brofman@pucpr.br

Artigo recebido em julho de 2004 Artigo aprovado em setembro de 2004 
observaram-se novos vasos no grupo de células tronco mesenquimais, no grupo de células mioblásticas esqueléticas, tecido muscular e angiogênese e miogênese no grupo cocultura.

Conclusão: A fração de ejeção do ventrículo esquerdo melhorou no grupo em que foram injetadas células musculares, mais acentuadamente no grupo co-cultura. Nos achados imunocitoquímicos, na cultura e no co-cultivo encontraram-se as células correspondentes. Nas espécimes cardíacas, foram encontradas células musculares e mioblásticas esqueléticas. Na histopatologia, encontraramse novos vasos, tecido muscular e ambos quando se injetou células tronco mesenquimais, células mioblásticas esqueléticas e a co-cultura das duas células, respectivamente.

Descritores: Transplante de células. Infarto do miocárdio, terapia. Miocárdio. Isquemia miocárdica. Cultura de células, utilização.

\section{Abstract}

Objective: To present the functional, immunocytochemical and histopathologic results (in vitro or in heart specimens) after isolation, culture and co-culture of mesenchymal stem cells and skeletal myoblast cells transplanted and cotransplanted in experimental animals with ischemic heart disease and left ventricular ejection fractions lower than $40 \%$.

Method: We utilized 72 Wistar rats, divided into four groups according to the culture media or injected cells: control group into which only culture media was injected $(22$ rats); mesenchymal stem cell group (17 rats); myoblast skeletal cell group (16 rats) and co-culture group (17 rats). In the immunohistochemical studies, the cells were stained with anti-vimentin, anti-desmin and anti-myosin. In the histopathologic analysis, slides were stained with Gomori Trichrome, and neo-vessels and muscle tissues were identified.

\section{INTRODUÇÃO}

A terapia celular tem sido utilizada na reparação de área fibrosada, conseqüente a infarto do miocárdio (IM) e diferentes tipos de células têm sido testadas [1]. A cardiomioplastia celular tem buscado a recuperação da função do órgão por meio de duas linhas de pesquisa: células para a miogênese e células para angiogênese cardíaca [2-4].

Para a primeira, têm sido utilizadas as células de músculo liso, progenitoras adultas multipotenciais de medula óssea, os mioblastos esqueléticos e os cardiomiócitos fetais e neonatais. Para a angiogênese cardíaca, têm sido empregadas as células endoteliais retiradas da camada íntima das artérias ou veias, tronco derivadas da medula óssea e progenitoras derivadas do sangue circulante [5].

Estas células foram individualmente injetadas ou em associação, em diferentes tipos de animais de
In the functional analysis the left ventricle ejection fraction was analyzed one week after myocardial infarction and one month after the injection.

Results: The initial left ventricle ejection fraction (control echo) was not statistically significant between the four groups $(P=0.276)$, but was significantly different in the follow-up examination $(P=0.001)$. This difference was seen between the control and the myoblast skeletal cells groups $(\mathrm{P}=\mathbf{0 . 0 3 7})$, between the control and the co-culture groups $(P<0.001)$, and between the mesenchymal stem cell and co-culture groups $(P=0.025)$. When the initial and final echocardiograms in each group were compared, the control group deteriorated $(P=0.005)$ and the co-culture group improved $(P=0.006)$. With the immunocytochemical in vitro analysis, mesenchymal stem cells were identified when stained with anti-vimentin and muscle cells when stained with anti-desmin. In the heart specimens, muscle tissue, stained with anti-desmin and skeletal myoblasts cells, stained with fast anti-miosin were identified. In the histopathologic analysis, new vessels were observed in the mesenchymal stem cell and skeletal myoblast groups, and muscular tissue, angiogenesis and myogenesis in the co-culture group.

Conclusion: The left ventricle ejection fraction improved in the group in which muscle cells were injected and more strikingly in the co-culture group. The immunohistochemical findings in the culture and co-culture groups evidenced the corresponding cells. In the heart specimens, muscle and skeletal myoblast cells were found. In the histopathologic examination, new vessels and muscle tissue were found in the mesenchymal stem cell, skeletal myoblast cell and coculture groups.

Descriptors: Cell transplantation. Myocardial infarction, therapy. Myocardium. Myocardial ischemia. Cell culture, utilization. experimentação [6-9] e em séries clínicas [10,11], com miocardiopatia isquêmica [12] ou dilatada [13].

Nesse trabalho é proposta uma nova opção para a miocardioplastia celular, em animais de laboratório com fração de ejeção de ventrículo esquerdo menor que $40 \%$, causada por miocardiopatia isquêmica.

Foram utilizadas nesse estudo células tronco mesenquimais de medula óssea (CTM) e células mioblásticas esqueléticas (ME) cultivadas isoladamente ou em co-cultura, transplantadas ou co-transplantadas. Foi avaliada a resposta funcional por meio do ecocardiograma bidimensional, que permitiu medir as frações de ejeções do ventrículo esquerdo (FEVE), em dois momentos do seguimento, e analisados os estudos imunocitoquímicos in vitro e após a eutánasia, e histopatológicos das espécimes cardíacas com um mês da cardiomioplastia. 


\section{MÉTODO}

Todos os experimentos foram realizados de acordo com os princípios de cuidados com animais de laboratório de acordo com a lei n ${ }^{\circ} 6638$ da República Federativa do Brasil que trata de normas para a prática didático-científica da vivissecção de animais [14].

O modelo utilizado para o desenvolvimento da miocardiopatia isquêmica foi por meio da ligadura da artéria coronariana e conseqüente infarto do miocárdio.

Os animais de laboratório empregados foram ratos Wistar, machos com peso entre 250 e 300 gramas. O infarto do miocárdio foi causado, sob anestesia geral, com os animais intubados, ventilados por aparelho respiratório (Harvard Apparatus, USA) por meio de toracotomia lateral esquerda. Após a exposição do coração, a artéria coronária interventricular anterior foi ligada, entre o átrio esquerdo e a via de saída do ventrículo direito com fio de polipropileno 7,0 (Ethicon, USA)

O transplante celular ou a injeção do meio de cultura foi realizado por meio de esternotomia mediana, após sete dias do IM, em uma única injeção sob a mesma técnica anestésica e ventilatória.

\section{Avaliação Ecocardiográfica}

Os animais foram analisados com equipamento de ecocardiografia bidimensional modelo Sonos 5500 (Hewlet Packard, USA), com transdutores setorial S12 $(5-12 \mathrm{mHz}) \mathrm{e}$ limiar 15L6 $(7-15 \mathrm{mHz})$ e a fração de ejeção do ventrículo esquerdo (FEVE) foi medida na posição para-esternal longitudinal, de acordo com o método de Simpson, com os animais sob anestesia geral.

\section{Método de Cultura Celular}

A obtenção das células foi realizada por duas diferentes maneiras, de acordo com o tipo celular.

\section{1) Células esqueléticas mioblásticas}

\section{Limpeza e maceração muscular}

O músculo tibial anterior foi retirado dos animais em uma câmara de fluxo laminar e foram colocados em uma placa com meio de cultura, com antibiótico a 1\% (penicilina $100 \mathrm{U} /$ $\mathrm{ml}$ e estreptomicina $100 \mu \mathrm{g} / \mathrm{ml}$ ). A seguir, com auxílio de uma lupa, foram retirados os vasos e os tecidos conjuntivos: aponeuroses e tecidos gordurosos e os fragmentos colocados em outra placa e segue-se a maceração.

\section{Digestão enzimática}

O botão de células do músculo foi diluído em Colagenose tipo IA (Sigma, USA) por uma hora, em incubadora de $\mathrm{CO}_{2}$ a $5 \%$ e a $37^{\circ} \mathrm{C}$ de temperatura e agitado a cada 10 minutos.

As células foram centrifugadas, o botão de células foi recuperado em tripsina - EDTA a 0,25\% (Gibco, USA) em incubadora. A digestão enzimática foi interrompida com soro fetal bovino (Gibco, USA).

\section{Filtração e semeadura}

O material foi filtrado e centrifugado, o botão de células recuperado e diluído em de meio de cultura DMEN (Dulbecco's Modified Eagle's Medium), suplementado com $15 \%$ de soro fetal bovino, $1 \%$ de antibiótico e $10 \%$ de IGF-I (fator de crescimento de insulina tipo I) e $10^{-7} \mathrm{M}$ de dexametaxona. A contagem das células foi realizada com auxílio da câmara de Neubauer.

As células foram cultivadas em média por 14 dias em meio de cultura e mantidas em estufa de $\mathrm{CO}_{2}$ a $5 \%$ e a $37^{\circ} \mathrm{C}$ de temperatura. $\mathrm{O}$ meio foi trocado duas a três vezes por semana e realizadas as subculturas de acordo com a confluência celular.

\section{2) Células mononucleares da medula óssea}

A coleta celular foi realizada por meio da técnica de punção e aspiração.

\section{Coleta das células}

Sob anestesia geral o animal foi colocado em decúbito lateral com o membro posterior em flexão, a punção da crista ilíaca foi realizada com uma seringa de $5 \mathrm{ml}$ heparinizada (liquemine $5000 \mathrm{U} / \mathrm{ml}$ ) com agulha $25 \times 8,21 \mathrm{G1}$ para aspiração. $\mathrm{O}$ material coletado foi processado utilizando-se um gradiente de densidade, Ficoll-Hipaque $(\mathrm{d}=1,077)$ de acordo como descrito por BOYUM, em 1968 [15]. Após 48 horas, o sobrenadante da cultura (linha hematopoética e debris) fo aspirado, restando aderidas as CTM. Foi realizada a contagem das células mononucleares da medula óssea com auxílio de câmara de Neubauer. O método de cultura foi semelhante com todas as células [16].

\section{Co-Cultura}

Após o isolamento celular conforme técnicas descritas acima, as células ME e as células mononucleares foram distribuídas em proporções de 2:1 e realizadas observações morfológicas, quanto à sobrevivência, à adesão ao substrato e à confluência. Após 48h, o sobrenadante da cultura (linha hematopoética e debris) foi aspirado dos frascos, restando aderidos apenas os ME, as CTM e os fibroblastos. As células foram cultivadas da maneira já descrita acima [17].

\section{Grupo de experimentação}

Setenta e dois ratos foram incluídos neste estudo e divididos em quatro grupos, de acordo com o meio de cultura ou das células injetadas: grupo controle em que foi injetado apenas o meio de cultura (22 ratos); grupo CTM (17 ratos), nos quais foram injetadas $2,5 \times 10^{6}$ células, grupos células ME (16 ratos) nos quais foram injetadas $5 \times 10^{6}$ células e 
grupo células em co-cultura (17 ratos) nos quais foram injetadas $7,5 \times 10^{6}$ células.

\section{Estudos imunocitoquímicos e}

\section{histopatológicos}

Durante a cultura in vitro, as células foram marcadas com anti-vimentiva para confirmar a presença de células CTM e com anti-desmina para as células musculares e nas espécimes, as células foram identificadas com os marcadores já descritos e acrescido do anti-miosina rápida que é um especifico para $\mathrm{ME}$.

Nos estudos histopatológicos realizados após a eutanásia dos animais (1 mês de seguimento), os cortes foram coradas com Tricrômio de Gomori e os achados foram interpretados por microscopia óptica.

\section{Análise Estatística}

Os quatro grupos foram comparados entre si e individualmente, em relação à FEVE, com uma semana após o IM e um mês após a injeção celular. Utilizou-se o teste ANOVA, o teste $t$ de Student para amostras pareadas e o teste exato de Fisher, considerando-se diferença estatística significante quando $\mathrm{p}<0,05$.

\section{RESULTADOS}

\section{Análise da função ventricular}

\section{Fração de ejeção do ventrículo esquerdo}

$\mathrm{Na}$ comparação das FEVE médias dos grupos no ecocardiograma de controle não se encontrou diferença estatística $(\mathrm{p}=0,276)$.

Na avaliação ecocardiográfica com um mês após a injeção, foi encontrada diferença estatística significativa entre a fração de ejeção média dos grupos $(\mathrm{p}=0,001)$. Essa diferença ocorreu entre o grupo controle e o grupo ME $(\mathrm{p}=0,037)$, entre o grupo controle e o grupo em co-cultura $(\mathrm{p}<0,001)$ e entre o grupo CTM e o grupo em co-cultura $(\mathrm{p}=0,025)$. Não se encontrou diferença estatística entre o grupo controle e o grupo CTM ( $\mathrm{p}=0,372)$, entre o grupo ME e o grupo CTM $(\mathrm{p}=0,263)$ e o grupo ME e o grupo em cocultura $(\mathrm{p}=0,267)$.

Quando comparamos as medidas, em cada grupo, entre os dois ecocardiogramas encontrou-se diferença significativa no grupo controle $(\mathrm{p}=0,005)$ e no grupo em cocultura $(p=0,006)$ e não foi encontrada essa diferença no grupo CTM $(0,65)$ e ME $(0,09)$.

Os resultados obtidos em relação à fração de ejeção são apresentados nas Tabelas 1 e 2 e na Figura 1.
Tabela 2. Fração de ejeção após 1 mês - comparações entre os grupos

\begin{tabular}{ll}
\hline Grupos comparados & $\mathrm{p}^{*}$ \\
\hline Controle x ME & 0,037 \\
Controle x CTM & 0,372 \\
Controle x Co-cultura & $<0,001$ \\
ME x CTM & 0,263 \\
ME x Co-cultura & 0,267 \\
CTM x Co-cultura & 0,025 \\
\hline
\end{tabular}

$\left(^{*}\right)$ Teste LSD $(\mathrm{p}<0,05)$; ME - células mioblásticas esqueléticas;

CTM - Células tronco mesenqimais de medula óssea

FRAÇĀO DE EJEÇĀO - BASE E ÅÓS 1 Mț

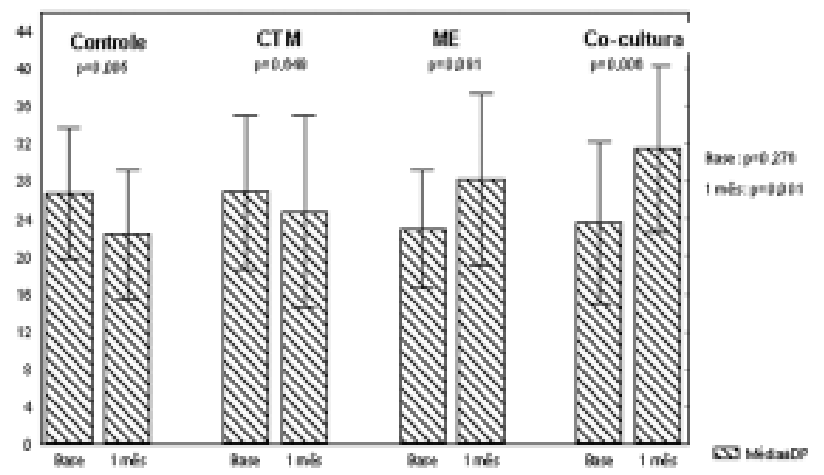

Fig. 1 - Fração de ejeção (FE) após 1 mês - comparação da FE de cada grupo entre o cardiograma de controle e após 1 mês de transplante. $(*)$ LSD test $(\mathrm{p}<0,05)$

\section{Estudo imunocitoquímico}

No estudo inumocitoquímico in-vitro, identificou-se CTM quando se marcou com anti-vimentiva e células musculares, com anti-desmina.

Na avaliação em espécimes após um mês do transplante, identificaram-se células musculares quando se marcou com anti-desmina e ME quando se marcou com anti-miosina rápida.

\section{Estudo histopatológico}

$\mathrm{Na}$ interpretação dos cortes corados com Tricrômio de Gomori, identificou-se tecido muscular no grupo em que 
essas células foram injetadas. No grupo em que se injetou CTM, identificou-se exclusivamente angiogênese, na zona do IM. No grupo co-cultura identificou-se angiogênese e miogênese na área de fibrose do VE (Figura 2).
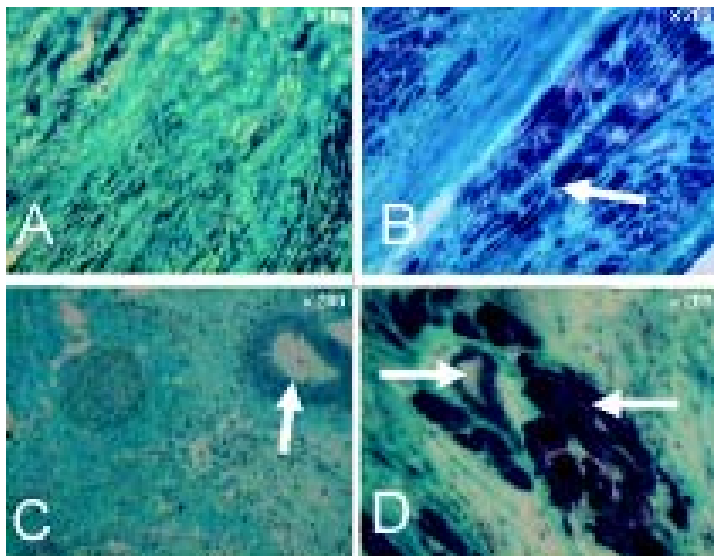

Fig. 2 - A-Microfotografia da cicatriz, após 1 mês de IM. BMicrofotografia do estudo histopatólogico, do grupo ME, identificando pela seta o tecido muscular transplantado. CMicrofotografia do estudo histopatólogico do grupo CTM, identificado pela seta a neoangiogênese. D-Microfotografia do estudo histopatólogico do grupo Co-cultura, identificados pelas setas a angiogênese e a miogênese. Os cortes histológicos foram corados com Tricrômio de Gomori e os aumentos estão identificados em cada microfotografia.

\section{COMENTÁRIOS}

A insuficiência cardíaca é determinada, entre outras causas, pela miocardiopatia isquêmica [18]. O uso da terapêutica medicamentosa, da angioplastia percutânea ou da operação de revascularização do miocárdio com enxertos vasculares, tem sido adotado para aliviar sintomas ou recuperar a oferta de nutrientes em área isquêmica sem, no entanto, regenerar os cardiomiócitos definitivamente lesados e responsáveis pelo comprometimento da função contrátil do coração [19].

O transplante cardíaco tem sido, até o momento, o único tratamento operatório que trata a causa e não o efeito da lesão das células cardíacas uma vez que o órgão é substituído. Entretanto, é limitado pelo pequeno número de doadores e o difícil seguimento pós-operatório [20].

Com o conhecimento da biologia molecular e celular, a terapia celular tem sido usada em diferentes doenças que, até então, eram intratáveis e incuráveis [21]. A terapia celular direcionada para o coração iniciou-se nos anos 90 , com a utilização experimental de cardiomiócitos fetais, evoluindo para a utilização de ME e de CTM $[22,23]$.

Tem-se buscado a recuperação da oferta de nutrientes e metabólicos através da angiogênese e de massa muscular através da miogênese. No início dos anos 2000, iniciou-se a utilização em séries clínicas e quem primeiro descreveu a utilização de ME na opção de recuperação da função contrátil do coração foi MENASCHÉ et al., em 2001 [10].

O estudo desenvolvido na PUCPR baseou-se na idéia de buscar sinergismos entre as células durante a cultura e de ofertar duas células diferentes na recuperação da cicatriz do IM, com o objetivo de desenvolver novos vasos para a perfusão e também massa muscular e com isso buscar, provavelmente, diminuir a alta mortalidade dessas células injetadas em área com baixa oferta de nutrientes e metabólicos, conforme tem sido descrito na literatura [1].

Desta forma, utilizou-se CTM e ME, sendo que a primeira tem o objetivo de angiogênese e a segunda, de miogênese.

Os achados imunocitoquímicos in vitro e nas espécimes cardíacas obtidas após um mês do transplante confirmaram a presença das células cultivadas em laboratório isoladamente e em co-cultura.

Nos estudos histopatológicos também realizados neste período, foram encontrados novos vasos no grupo em que se injetou CTM, células musculares no grupo ME e angiogênese e miogênese no grupo em que se transplantaram as duas células co-cultivadas.

$\mathrm{Na}$ análise da função de ejeção do VE, não se observou diferença estatística nas medidas obtidas do ecocardiograma controle entre os quatro grupos.

Na avaliação após um mês do transplante, encontrou-se diferença estatística entre os grupos. Na comparação entre esses, se observou diferença estatística entre o grupo controle e o grupo ME, entre o grupo controle e o grupo em co-cultura e o grupo CTM e o grupo em co-cultura o que permite inferir que nos grupos transplantados com células musculares isoladas ou em co-cultura ocorre melhora da função cardíaca.

Em cada grupo, na comparação entre as duas avaliações, observou-se diferença estatística no grupo controle para pior e no grupo co-cultura para melhor. No grupo CTM e no grupo ME não ocorreu diferença estatística, apesar da fração de ejeção ter aumentado neste último grupo.

\section{CONCLUSÃO}

Os achados ecocardiográficos, imunocitoquímicos e histopatológicos permitiram concluir que:

- a fração de ejeção do VE, melhorou exclusivamente nos grupos em que se transplantaram células musculares isoladas ou em co-cultura e que no grupo co-cultura a recuperação dessa medida foi a mais significativa entre os grupos utilizados neste estudo.

- durante o co-cultivo tem-se a presença das duas células (TMC e ME), que os diferentes tipos de células foram encontrados isoladamente ou em conjunto de acordo com as células injetadas e que no grupo CTM, encontraram-se apenas novos vasos, no grupo ME, apenas células musculares e no grupo co-cultura, a presença de angiogênese e miogênese. 


\section{REFERÊNCIAS BIBLIOGRÁFICAS}

1. Menasche P. Cell transplantation in myocardium. Ann Thorac Surg 2003,75(6 suppl):S20-8.

2. Taylor DA, Atkins BZ, Hungspreugs P, Jones TR, Reedy MC, Hutcheson KA et al. Regenerating functional myocardium: improved performance after skeletal myoblast transplantation. Nat Med 1998;4:929-33.

3. Kocher AA, Schuster MD, Szabolcs MJ, Takuma S, Burkhoff $\mathrm{D}$, Wang J et al. Neovascularization of ischemic myocardium by human bone-marrow derived angioblasts prevents cardiomyocyte apoptosis, reduces remodeling and improves cardiac function. Nat Med 2001;7:430-6.

4. Kim EJ, Li RK, Weisel RD, Mickle DA, Jia ZQ, Tomita S et al Angiogenesis by endothelial cell transplantation. J Thorac Cardiovasc Surg 2001;122:963-71.

5. Cardoso F, Gonçalez JH, Ezquerra. Pespectivas futuras de tratamento em la insuficiência cardíaca: utilización de células madre para la regeneración miocárdica. Rev Arg Cir Cardiovasc 2003;1:15-24.

6. Li RK, Jia ZQ, Weisel RD, Mickle DA, Zhang J, Mohabee MK et al. Cardiomyocyte transplantation improves heart function. Ann Thorac Surg 1996;62:654-61.

7. Tomita S, Mickle DA, Weisel RD, Jia ZQ, Tumiati LC, Allidina $Y$ et al. Improved heart function with myogenesis and angiogenesis after autologous porcine bone marrow stromal cell transplantation. J Thorac Cardiovasc Surg 2002;123:1132-40.

8. Strauer BE, Brehm M, Zeus T, Kostering M, Hernandez A, Sorg RV et al. Repair of infarcted myocardium by autologous intracoronary mononuclear bone marrow cell transplantation in humans. Circulation 2002;106:1913-8.

9. Ghostine S, Carrion C, Souza LC, Richard P, Bruneval P, Vilquin $\mathrm{JT}$ et al. Long-term efficacy of myoblast transplantation on regional structure and function after myocardial infarction. Circulation 2002;106(suppl 1):I131-6.

10. Menasche P, Hagege AA, Scorsin M, Pouzet B, Desnos M, Duboc D et al. Myoblast transplantation for heart failure. Lancet 2001;357:279-80.

11. Perin EC, Dohmann HF, Borojevic R, Silva SA, Sousa AL, Mesquita CT et al. Transendocardial, autologous bone marrow cell transplantation for severe, chronic ischemic heart failure. Circulation 2003;107:2294-302.

12. Assmus B, Schachinger V, Teupe C, Britten M, Lehmann R, Dobert $\mathrm{N}$ et al. Transplantation of Progenitor Cells and Regeneration Enhancement in Acute Myocardial Infarction (TOPCARE-AMI). Circulation 2002;106:3009-17.
13. Soares MB, Lima RS, Rocha LL, Takyia CM, Pontes-deCarvalho L, de Carvalho AC et al. Transplanted bone marrow cells repair heart tissue and reduce myocarditis in chronic chagasic mice. Am J Pathol 2004;164:441-7.

14. Brasil. Lei Federal n.? 6.638. Estabelece normas para a prática didático-científica da vivissecção de animais e determina outras providências. Diário Oficial da União, Brasília, p.1, 10 de maio de 1979.

15. Boyum A. Isolation of mononuclear cells and granulocytes from human blood: isolation of monuclear cells by one centrifugation, and of granulocytes by combining centrifugation and sedimentation at $1 \mathrm{~g}$. Scand J Clin Lab Invest Suppl 1968;97:77-89.

16. Carvalho KA, Guarita-Souza LC, Rebelatto CL, Senegaglia AC, Hansen P, Mendonça JG et al. Could the coculture of skeletal myoblasts and mesenchymal stem cells be a solution for postinfarction myocardial scar? Transplant Proc 2004;36:991-2.

17. Carvalho KA, Guarita-Souza LC, Rebelatto CL, Senegaglia AC, Hansen P, Mendonca JG et al. Aneural culture of rat myoblasts of myocardial transplant. Transplant Proc 2004;36: $1023-4$.

18. Pfeffer MA. Left ventricular remodeling after acute myocardial infarction. Annu Rev Med 1995; 46:455-66.

19. Ryan TJ, Antman EM, Brooks NH, Califf RM, Hillis LD, Hiratzka LF et al. 1999 update: ACC/AHA guidelines for management of patients with acute myocardial infarction: a report of the American College of Cardiology/ American Heart Association Task Force on Practice Guidelines (Committee on Management of Acute Infarction) J Am Coll Cardiol 1999;34:890-911.

20. Bocchi EA, Fiorelli A; First Guideline Group for Heart Transplantation of the Brazilian Society of Cardiology. The Brazilian experience with heart transplantation: a multicenter report. J Heart Lung Transplant 2001;20:637-45.

21. Pittenger MF, Mackay AM, Beck SC, Jaiswal RK, Douglas R, Mosca JD et al. Multilineage potential of adult human mesenchymal stem cells. Science 1999;284:143-7.

22. Scorsin M, Hagege A, Vilquin JT, Fiszman M, Marotte F, Samuel JL et al. Comparison of the effects of fetal cardiomyocyte and skeletal myoblast transplantation on postinfarction left ventricular function. J Thorac Cardiovasc Surg 2000;119:1169-75.

23. Brofman PRS, Carvalho K, Guarita-Souza LC. Cell transplantation: a new option for treating cardiomyopathy. Prog Biomed Res 2003;8:67-8. 